\title{
ARD
}

\section{A plant-derived glucocorticoid receptor modulator attenuates inflammation without provoking ligand-induced resistance}

\author{
V Gossye, D Elewaut, K Van Beneden, et al. \\ Ann Rheum Dis 2010 69: 291-296 originally published online February 9, \\ 2009 \\ doi: 10.1136/ard.2008.102871
}

Updated information and services can be found at:

http://ard.bmj.com/content/69/01/291.full.html

\begin{tabular}{cl}
\hline References & $\begin{array}{l}\text { These include: } \\
\text { This article cites } 26 \text { articles, } 11 \text { of which can be accessed free at: } \\
\text { http://ard.bmj.com/content/69/01/291.full.html\#ref-list-1 } \\
\text { Article cited in: } \\
\text { http://ard.bmj.com/content/69/01/291.full.html\#related-urls }\end{array}$ \\
$\begin{array}{c}\text { Email alerting } \\
\text { service } \\
\text { Tolleceive free email alerts when new articles cite this article. Sign up in the } \\
\text { box at the top right corner of the online article. }\end{array}$ & $\begin{array}{c}\text { Articles on similar topics can be found in the following collections } \\
\text { Immunology (including allergy) (44867 articles) } \\
\text { Inflammation (13765 articles) } \\
\text { Degenerative joint disease (9684 articles) } \\
\text { Musculoskeletal syndromes (17209 articles) } \\
\text { Guidelines (1041 articles) }\end{array}$ \\
\hline
\end{tabular}

Notes

To request permissions go to:

http://group.bmj.com/group/rights-licensing/permissions

To order reprints go to:

http://journals.bmj.com/cgi/reprintform

To subscribe to BMJ go to:

http://journals.bmj.com/cgi/ep 


\title{
A plant-derived glucocorticoid receptor modulator attenuates inflammation without provoking ligand- induced resistance
}

\author{
V Gossye, ${ }^{1}$ D Elewaut, ${ }^{2} \mathrm{~K}$ Van Beneden, ${ }^{2}$ P Dewint, ${ }^{2} \mathrm{G}$ Haegeman, ${ }^{1} \mathrm{~K}$ De Bosscher ${ }^{1}$
}

${ }^{1}$ Ghent University, Department of Physiology, Laboratory for Eukaryotic Gene Expression and Signal Transduction (LEGEST), Gent, Belgium; ${ }^{2}$ Ghent University Hospital, Department of Rheumatology, Gent, Belgium

Correspondence to:

Professor Dr G Haegeman,

LEGEST, KL Ledeganckstraat 35,

B-9000 Gent, Belgium; Guy.

Haegeman@UGent.be

Accepted 23 January 2009

Published Online First

8 February 2009

\section{ABSTRACT}

Background: Acquired resistance to glucocorticoids constitutes a major clinical challenge, often overlooked in the search for improved alternatives to classic steroids. We sought to unravel how two glucocorticoid receptoractivating compounds, dexamethasone and Compound A, influence glucocorticoid receptor levels and how this can be correlated to their gene regulatory potential.

Methods: Compound A and dexamethasone were applied in a short-term and long-term treatment protocol. By quantitative PCR analysis in fibroblast-like synoviocytes (FLS) the gene regulatory potential of both compounds in the two experimental conditions was analysed. A parallel Western blot assay revealed the glucocorticoid receptor protein levels in both conditions (ex vivo). In addition, this study examined the effect of systemic administration of dexamethasone and Compound $A$, in concentrations effective to inhibit collagen-induced arthritis, in DBA/1 mice on glucocorticoid receptor levels (in vivo).

Results: Compound A does not induce a homologous downregulation of glucocorticoid receptor in vivo and ex vivo, thereby retaining its anti-inflammatory effects after prolonged treatment in FLS. This is in sharp contrast to dexamethasone, showing a direct link between prolonged dexamethasone treatment, decreasing glucocorticoid receptor levels, and the abolishment of inflammatory gene repression in FLS. It was also observed that the acquired low receptor levels after prolonged dexamethasone treatment are still sufficient to sustain the transactivation of endogenous glucocorticoid-responsive element-driven genes in FLS, a mechanism partly held accountable for the metabolic side-effects.

Conclusion: Compound $\mathrm{A}$ is less likely to evoke therapy resistance, as it does not lead to homologous glucocorticoid receptor downregulation, which is in contrast to classic glucocorticoids.

Sixty years after the first chemical synthesis of cortisone, also known as compound E, glucocorticoids remain the cornerstone drugs used in treatment protocols of a wide range of inflammatory and immune disorders. ${ }^{1}$ However, and although the first impressions were very positive, it soon became clear that the frequent and prolonged administration of glucocorticoids influences a diverse set of key biological functions and causes severe, sometimes irreversible, side-effects. ${ }^{2}$ In this respect, we have to recognise that, if glucocorticoids were to be discovered today, they would probably face difficulties in order to obtain regulatory approval. Nevertheless, despite the ongoing interest and efforts of both the academic world and the pharmaceutical industry, no other drug has been able to compete with glucocorticoids regarding their anti-inflammatory effect, therapeutic benefit, the variety of applications and the number of patients treated. As such, continued efforts are made to find and synthesise compounds with the same anti-inflammatory effects as classic steroids, yet with reduced side-effects. ${ }^{3}$

From a molecular point of view, it is hypothesised that the unwanted effects of glucocorticoids can be separated from their beneficial effects. Glucocorticoids are small lipophilic molecules that diffuse freely through the cell membrane to interact with the glucocorticoid receptor. The ligand-mediated activation of the glucocorticoid receptor evokes a conformational change, allowing the receptor to translocate to the nucleus and to influence gene expression in a positive (transactivation) and in a negative manner (transrepression). To exert its transactivation function the glucocorticoid receptor binds to glucocorticoid-responsive elements (GRE) in the promoter of glucocorticoidresponsive genes. However, for its transrepression function the glucocorticoid receptor interferes with the functionality of other transcription factors, eg, the pro-inflammatory transcription factor nuclear factor kappa B $(\mathrm{NF}-\kappa \mathrm{B}){ }^{4}{ }^{5}$ It is believed that glucocorticoid receptor modulators that predominantly induce repression over activation display an improved safety profile, and the many new patent applications arising in this field indicate that this research area continues to be of great interest. ${ }^{3}$

In this respect, we characterised Compound $\mathrm{A}, \mathrm{a}$ stable analogue of the hydroxyphenyl aziridine precursor found in the Namibian shrub Salsola tuberculatiformis Botschantzev ${ }^{6}$ (fig 1) as a selective glucocorticoid receptor modifier, dissociating glucocorticoid receptor-mediated transrepression from its transactivation function in vitro.' The antiinflammatory potential of Compound $A$ was furthermore confirmed in vivo in the zymosaninduced arthritis model and in the collagen-induced arthritis (CIA) model, concomitantly in the absence of the unwanted diabetogenic effects. ${ }^{78}$ However, in addition to the side-effects associated with prolonged glucocorticoid treatment, it has been reported that approximately $30 \%$ of patients fail to respond to even high doses of glucocorticoids. ${ }^{9} 10$ Moreover, even though some patients initially seem to benefit from glucocorticoid therapy, they can eventually develop resistance. ${ }^{11}$ Different molecular mechanisms have been hypothesised to explain the phenomenon of acquired glucocorticoid resistance. In this context, it has been proposed that the cellular sensitivity to 
glucocorticoids is directly proportional to the receptor concentration. ${ }^{12-14}$ Consequently, the downregulation of glucocorticoid receptor levels observed after ligand treatment, ${ }^{15}$ which is in se a protection mechanism to safeguard the cell from continued signalling in the presence of ligand, ${ }^{12} 16$ may impede their widespread therapeutic use.

Notwithstanding, this unresponsiveness constitutes a major therapeutic challenge, ${ }^{11}{ }^{18}$ and this aspect is often overlooked in the search for improved ligands. We thus studied the effect of prolonged treatment with Compound A and the synthetic glucocorticoid dexamethasone on the homologous downregulation of the glucocorticoid receptor. In addition, we unravelled how this homologous downregulation affects the ability of the glucocorticoid receptor to repress pro-inflammatory cytokine expression and to induce GRE-driven gene expression. As an exvivo working model, we used a physiologically relevant system to rheumatoid arthritis (RA), fibroblast-like synoviocytes (FLS) isolated from the inflamed synovium of RA patients.

\section{MATERIAL AND METHODS}

\section{Isolation and culture of cells}

FLS cells were obtained from patients with active RA, according to the revised criteria of the American College of Rheumatology. ${ }^{19}$ The study was approved by the local ethics committee. Isolation and culturing of the FLS was performed as described previously. ${ }^{8}$

\section{Cytokines and reagents}

Recombinant murine TNF was produced in our laboratory. ${ }^{20}$ Dexamethasone was purchased from Sigma (St Louis, Missouri, USA). Compound A, 2-(4-acetoxyphenyl)-2-chloro- $N$-methylethylammonium chloride was produced and stored as described ${ }^{6}$ (Alexis Biochemicals, Lausen, Switzerland). Anti-glucocorticoid receptor (H-300) and anti-p42/p44 (extracellular signal-regulated kinase; ERK) were purchased from Santa Cruz Biotechnology (Santa Cruz, California, USA) and from Cell Signalling (Beverly, Massachusetts, USA), respectively. The human inflammation antibody array III was purchased from RayBiotech (Norcross, Georgia, USA) and was probed with cultivation medium of RA FLS, which had been on the cells for 3 days.

\section{DBA/1 mice}

Male 8-12-week-old DBA/1 mice were purchased from Janvier (LeGenest Saint Isle, France) and housed following institutional guidelines. All animal procedures were approved by the institutional animal care and ethics committee. For the

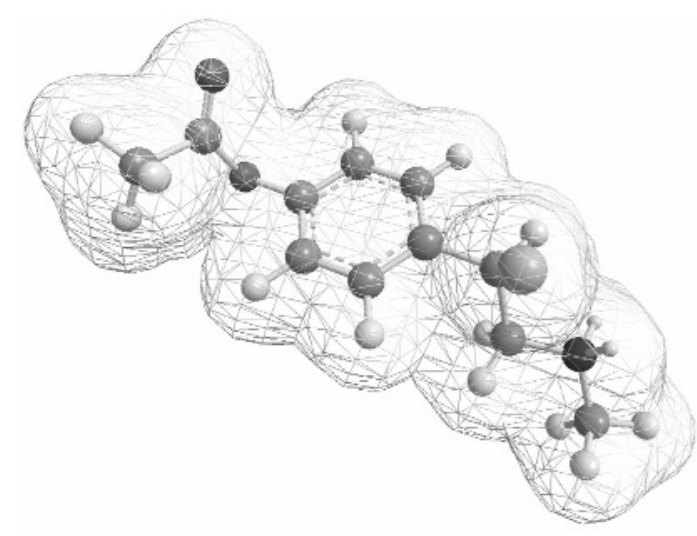

Figure 1 Chemical structure of Compound A. detection of homologous downregulation in vivo, DBA/1 mice were randomly assigned and were, during a period of 8 days, treated daily with phosphate-buffered saline (PBS; $200 \mu \mathrm{l}$ ), dexamethasone $(20 \mu \mathrm{g}$ dissolved in $200 \mu \mathrm{l} \mathrm{PBS})$ or Compound A (300 $\mu \mathrm{g}$ dissolved in $200 \mu \mathrm{l}$ PBS), after which they were killed and their livers isolated. For the isolation of RNA, as well as the reverse transcription of messenger RNA from FLS and murine liver tissue, we refer to the previously described protocol. ${ }^{8}$ The induction of CIA in DBA/1 mice is described in Dewint et al. ${ }^{8}$ The clinical severity of arthritis paws was graded according to standard evaluation procedures. For more details refer to Dewint et al. ${ }^{8}$

\section{Western blot analysis}

FLS were seeded in six-well plates and grown to subconfluence before induction. Total protein was extracted and equal amounts of protein ${ }^{21}$ were subjected to Western blotting. ${ }^{22}$

\section{Quantitative PCR}

For the isolation of RNA, as well as the reverse transcription of mRNA from FLS and murine liver tissue, we refer to the previously described protocol. ${ }^{8}$ The complementary DNA obtained was amplified by a quantitative PCR reaction with $\mathrm{iO}$ Custom SYBR Green Supermix (Biorad, Hercules, California, USA).

\section{Statistical analysis}

All analyses were performed with the commercially available statistical package GraphPad Prism 4. For normally distributed continuous data differences between groups were explored by one-way analysis of variance, followed by a Dunnett's multiple comparison test. If Gaussian distribution was not assumed, statistical significance was determined by means of the MannWhitney test.

\section{RESULTS}

We recently reported on the potential of Compound $A$ to attenuate CIA in DBA/1 mice. ${ }^{8}$ We here confirm that a clear anti-inflammatory response can be observed when mice were administered daily, for a period of 8 days, with Compound A $(300 \mu \mathrm{g})$ or dexamethasone $(20 \mu \mathrm{g})$ in comparison with PBStreated animals (fig 2A). The mean clinical severity chart clearly shows that PBS-treated mice show a significant increase in clinical severity from the day of onset of arthritis (termed day 1 in fig 2A) to the end of the experiment, 8 days later (termed day 8 in fig 2A). Treatment of the mice with dexamethasone or Compound $\mathrm{A}$, on the other hand, efficiently inhibits further progression of arthritis (fig $2 \mathrm{~A}$ ). ${ }^{8}$ Surprisingly, we noticed that the concentrations of dexamethasone used had a significant downregulatory effect on the glucocorticoid receptor concentration levels in $\mathrm{DBA} / 1$ mice liver tissue. In sharp contrast, systemic treatment of the mice with Compound A $(300 \mu \mathrm{g})$ did not affect glucocorticoid receptor expression levels in vivo (fig 2B). Also ex vivo, when FLS derived from patients with RA were treated with dexamethasone, a fast and significant reduction in glucocorticoid receptor protein levels could be observed. The results of a time-kinetics experiment in FLS, wherein FLS were treated with dexamethasone $(1 \mu \mathrm{M})$, Compound $\mathrm{A}(10 \mu \mathrm{M})$ or solvent $(\mathrm{EtOH})$ for $3,6,9$ or $24 \mathrm{~h}$, demonstrate that although there is not a significant decline in glucocorticoid receptor protein levels in FLS after $3 \mathrm{~h}$ of dexamethasone treatment, a clear decrease in receptor concentrations can be observed when dexamethasone is added for 6, 9 or $24 \mathrm{~h}$ (fig 2C). After treatment of the cells with Compound A, 

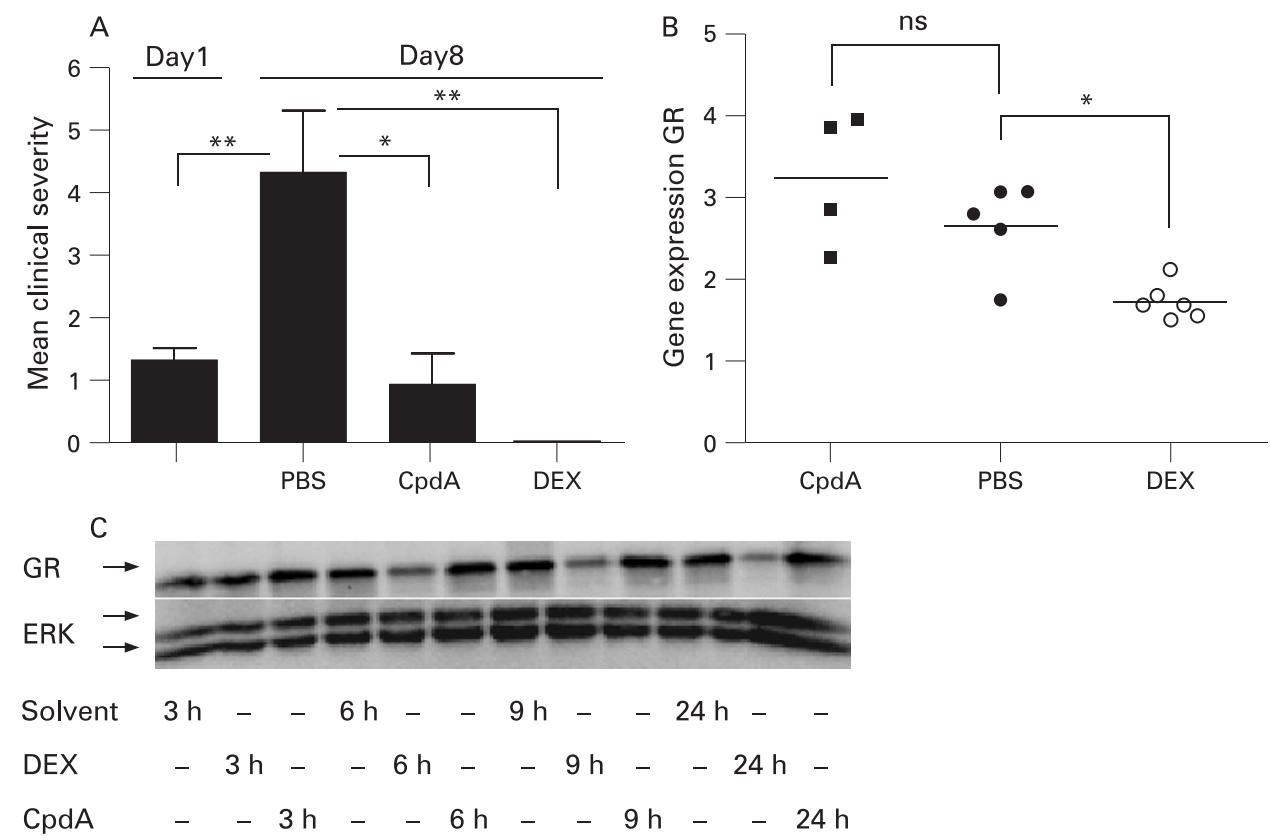

Figure 2 (A) Daily treatment with Compound A (CpdA; $300 \mu \mathrm{g}$ ) or dexamethasone (DEX; $20 \mu \mathrm{g}$ ) inhibits the further development of collagen-induced arthritis. Statistical significance was determined with the Mann-Whitney test, two-tailed $p$ value (day 1 vs phosphate-buffered saline (PBS) (day 8) ${ }^{* *} p=0.0019$; PBS vs dexamethasone ${ }^{* *} p=0.0095$; PBS vs Compound $A{ }^{*} p=0.0140$ ). Note that the clinical severity score was 0 for all the animals treated with dexamethasone. (B) After 8 days of treatment, liver samples were taken from the PBS, dexamethasone (20 $\mu \mathrm{g})$ or Compound A (300 $\mu \mathrm{g})$ treated DBA/1 mice. Quantitative PCR analysis was performed for the detection of glucocorticoid receptor (GR) in the different samples. Gene expression of the housekeeping gene hypoxanthine-guanine phosphoribosyltransferase (HPRT) was used for normalisation. Statistical significance was determined with the Mann-Whitney test, two-tailed $p$ value (PBS vs Compound A $p=0.4127$ (non-significant, ns); PBS vs dexamethasone $\left.{ }^{*} p=0.0173\right)$. (C) Fibroblast-like synoviocytes were treated with dexamethasone $(1 \mu \mathrm{M})$, Compound $\mathrm{A}(10 \mu \mathrm{M})$ or solvent $(\mathrm{EtOH})$ for $3,6,9$ or $24 \mathrm{~h}$ as indicated in the figure. Western blot analysis was performed on total protein extracts with an anti-glucocorticoid receptor antibody. The detection of extracellular signal-regulated kinase (ERK) was used as a loading control.

such an effect could not be observed at any of the investigated time points.

We reasoned that this mechanism of homologous downregulation may drastically affect the cellular sensitivity of primary human RA FLS to glucocorticoid therapy. To correlate the homologous downregulation of glucocorticoid receptor with the anti-inflammatory potential of both compounds, we compared the therapeutic potential of both compounds in two different experimental settings. In the first setup we pretreated the FLS with solvent, dexamethasone $(1 \mu \mathrm{M})$ or Compound $\mathrm{A}(10 \mu \mathrm{M})$ for $1 \mathrm{~h}$, after which TNF was added for $6 \mathrm{~h}$. The anti-inflammatory agents dexamethasone and Compound A thus resided on the FLS for a timespan of $7 \mathrm{~h}$, hereby mimicking a short-term treatment protocol. Alternatively, we pretreated the cells with solvent, dexamethasone $(1 \mu \mathrm{M})$ or Compound $\mathrm{A}(10 \mu \mathrm{M})$ for $24 \mathrm{~h}$, after which TNF was added for 6 h. Dexamethasone and Compound A were thus kept on the cells for $30 \mathrm{~h}$, reflecting a prolonged treatment protocol. Before analysing the results of the short-term and long-term treatment protocols, we first confirmed the significance of the pro-inflammatory mediators IL-6, IL-8 and macrophage chemoattractant protein 1 (MCP-1 $)^{23} 24$ on the basis of a human inflammation array and indeed identified these three markers as the most prominent pro-inflammatory mediators expressed by RA FLS (fig 3A). We observed that, when dexamethasone is added to the FLS for a short treatment protocol, the amounts of glucocorticoid receptor are sufficient to downregulate the TNF-induced gene expression of MCP-1, IL-8 and IL-6 efficiently (fig 3B). However, when administered for a prolonged time to FLS, dexamethasone failed to repress TNF-induced MCP-1, IL-8 and IL-6 expression (fig 3B). A parallel Western blot experiment confirmed that, in the prolonged treatment protocol, the effect of dexamethasone on the glucocorticoid receptor protein levels became more pronounced than in the short-term treatment protocol, thereby explaining the abolishment of its anti-inflammatory effect (fig 3B). Very interestingly, our data show that Compound A did not reduce the glucocorticoid receptor levels in RA FLS, and this is reflected by its efficiency in repressing pro-inflammatory cytokine expression, even on a long-term basis. Indeed, even after prolonged treatment, Compound $\mathrm{A}$ was still able to repress the expression of IL-6, IL-8 and MCP-1 in FLS efficiently (fig 3B).

As it is well known that glucocorticoids not only influence gene expression in a negative way, but additionally induce the expression of GRE-driven genes, we questioned how these lower glucocorticoid receptor levels influence the transactivation capacity of the receptor. Our data show that under conditions in which dexamethasone failed to exert its anti-inflammatory effects (prolonged treatment protocol), ie, when glucocorticoid receptor protein levels are low, this glucocorticoid was still able to induce procollagen C-endopeptidase enhancer 2 (PCOLCE2) and glutamine synthetase (GS) expression (fig $3 C$ ), a late response gene and an early response gene, respectively. In parallel with what we found before, Compound A, being a dissociated glucocorticoid receptor modulator, does not support the upregulation of GRE-driven genes, exemplified by PCOLCE2 $2^{8}$ and GS (fig 3C).

\section{DISCUSSION}

In this report, we highlight an intriguing molecular aspect of glucocorticoid receptor biology, which has to be borne in mind 
A
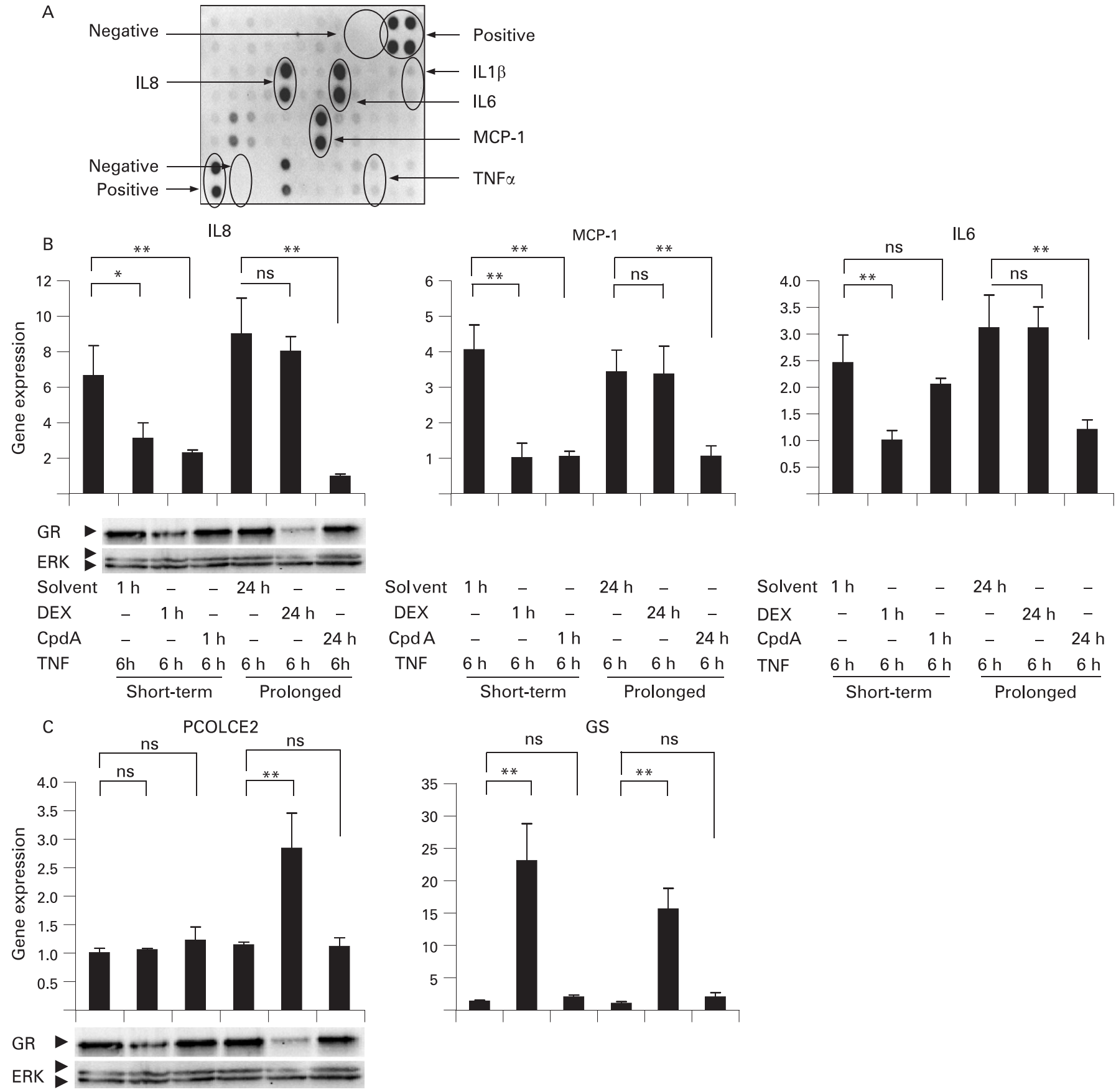

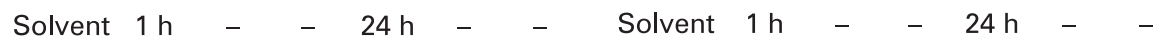

$$
\begin{aligned}
& \text { DEX - } 1 \mathrm{~h}-\quad-24 \mathrm{~h}- \\
& \text { CpdA - }-1 \mathrm{~h}-\quad-24 \mathrm{~h} \\
& \text { TNF } \frac{6 \mathrm{~h} \quad 6 \mathrm{~h} \quad 6 \mathrm{~h}}{\text { Short-term }} \quad \frac{6 \mathrm{~h} \quad 6 \mathrm{~h} \quad 6 \mathrm{~h}}{\text { Prolonged }}
\end{aligned}
$$

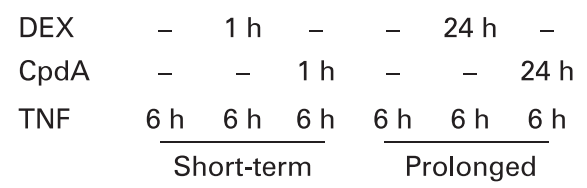

Figure 3 (A) The human inflammation array was incubated with medium of cultured fibroblast-like synoviocytes (FLS) and developed following the manufacturer's instruction. (B and C) FLS were pretreated with solvent, dexamethasone (DEX; $1 \mu \mathrm{M})$ or Compound $A$ (CpdA; $10 \mu \mathrm{M})$ for $1 \mathrm{~h}$ (shortterm treatment protocol) or $24 \mathrm{~h}$ (prolonged treatment protocol), as indicated in the figures. Afterwards, TNF (2000 units/ml) was added for $6 \mathrm{~h}$. Expression of the pro-inflammatory mediators macrophage chemoattractant protein 1 (MCP-1), IL-8 and IL-6, as well as of the glucocorticoidresponsive element-driven genes PCOLCE2 and GS, was monitored by means of quantitative PCR. Gene expression of the housekeeping gene HPRT was used for normalisation. Statistical significance was determined by one-way analysis of variance $\left({ }^{n s} p>0.05 ;{ }^{*} p<0.05 ;{ }^{* *} p<0.01\right)$. Dexamethasone and Compound A-treated samples were compared with the corresponding TNF-induced samples with Dunnett's multiple comparison test. One representative experiment is shown and results represent mean (SD) of a triplicate experiment. Western blot analysis was performed in parallel on total extracts with an anti-glucocorticoid receptor (GR) antibody. The detection of extracellular signal-regulated kinase (ERK) was used as a loading control. 
when developing new, improved glucocorticoid receptor activators. Although the aspect of homologous downregulation of the glucocorticoid receptor has already been reported extensively, even in peripheral blood mononuclear cells of patients with rheumatic disease, ${ }^{25}$ a direct link with the anti-inflammatory potential of these drugs has, to our knowledge, never been proved. Indeed, different molecular mechanisms have been linked to the complex phenomenon of glucocorticoid resistance, including overexpression of the glucocorticoid receptor $\beta$ isoform, an altered expression of membrane-bound glucocorticoid receptor, activity of the multidrug resistance pump and the increased activation of inflammatory signalling cascades, including STAT5, activator protein $1, \mathrm{NF}-\kappa \mathrm{B}$ and mitogenactivated protein kinase. ${ }^{14}$ Although the negative influence of $\mathrm{NF}-\kappa \mathrm{B}$ on glucocorticoid signalling has been linked to a mutual cross-talk mechanism, ${ }^{13}$ the detrimental effects of mitogenactivated protein kinase on glucocorticoid responsiveness have been attributed to an altered phosphorylation status of the receptor, which can drastically affect glucocorticoid receptor ligand binding (reducing the binding affinity or $\mathrm{Kd}$ ), Hsp90 interactions, subcellular localisation and transactivation potential of the receptor. ${ }^{14}$ However, the results presented in this study show that primary FLS isolated from the inflamed synovium of arthritis patients are only initially responsive to the therapeutic effects of dexamethasone, ie, after a short-term treatment protocol. These results indicate that the unresponsiveness of FLS to the anti-inflammatory properties of dexamethasone is not an intrinsic property of the cells. When the cells are treated with this steroid for a prolonged time, on the other hand, FLS become insensitive to the anti-inflammatory effect of dexamethasone. In line with this, we noticed that the acquired resistance to glucocorticoids coincides with a firm downregulation of glucocorticoid receptor protein levels in FLS. Previous molecular studies on glucocorticoid receptor homologous downregulation mainly focused on GRE-driven gene expression, and concluded that the remaining receptors are competent to respond to hormone, albeit with reduced efficiencies. ${ }^{17}$ However, our data reveal a more complex pattern of gene regulation after prolonged steroid treatment. Evidence is provided showing that homologous downregulation of glucocorticoid receptor in FLS from RA patients has major effects on the transrepression function of the receptor, in contrast to its influence on the transactivation function. Notwithstanding some exceptions, a body of evidence supports the belief that the transrepression function of the receptor is mainly responsible for the anti-inflammatory effects, whereas its transactivation function is held accountable for most of the metabolic sideeffects. Therefore, it is not surprising that some patients, who slowly develop resistance to the therapeutic effects of glucocorticoids, still display many of the unwanted effects associated with prolonged glucocorticoid treatment. ${ }^{26}$ By confirming our data on homologous downregulation after dexamethasone treatment in vivo in liver tissue of $\mathrm{DBA} / 1$ mice, we indicate that this phenomenon is not restricted to sites of inflammation, but rather represents a general effect on the organism.

Consequently, these findings open up new avenues for the development of glucocorticoid receptor modulators, not only with an improved benefit to the side-effect ratio, but also with the perspective that ligand-induced resistance may well be avoidable, an aspect that has often been overlooked in the past. We provide here proof of principle that such molecules may be found. Indeed, although it has been stated before that glucocorticoid receptor modulators that induce glucocorticoid receptor activation and subsequent nuclear translocation all induce a homologous downregulation of the receptor, ${ }^{15}$ we here show that the glucocorticoid receptor-activating Compound A, ${ }^{7}$ which induces nuclear translocation of the receptor in FLS, ${ }^{8}$ does not evoke ligand-induced downregulation in the ex-vivo patient material. The molecular basis for the differences in glucocorticoid receptor gene regulation after dexamethasone and Compound A treatment is not yet clear, but various hypotheses can be put forward. First, it is possible that Compound A elicits a different conformational change of the receptor compared with dexamethasone, ${ }^{7}$ which is not recognised by the ubiquitination machinery. Alternatively, it is known that phosphorylation is a positive signal for degradation. ${ }^{27}$ In this respect, it is interesting to note that differences in the phosphorylation status of glucocorticoid receptors can be observed after the treatment of lung carcinoma cells with Compound A versus dexamethasone. ${ }^{7}$ Note that the above hypotheses reflect posttranslational mechanisms to regulate the levels of glucocorticoid receptor protein. However, in DBA/1 mice a decrease in receptor levels could already be observed at the mRNA level, implying that the glucocorticoid receptor promoter and its accessory proteins can differentiate between dexamethasone and Compound A-activated glucocorticoid receptor. In conclusion, it is possible that the higher levels of glucocorticoid receptor protein observed after Compound A treatment compared with dexamethasone treatment reflect a combination of molecular events occurring at different levels of gene and protein regulation. Nonetheless, we hypothesised and confirmed that Compound $\mathrm{A}$, in contrast to dexamethasone, retains its antiinflammatory potential even after prolonged treatment, a finding with significant therapeutic interest for many chronic inflammatory diseases in need of long-term immunosuppression therapies.

Acknowledgements: The authors would like to thank Ann Vervloet for technical assistance.

Funding: VG is a predoctoral researcher supported by the Instituut voor de Aanmoediging van Innovatie door Wetenschap en Technologie in Vlaanderen. KDB and KVB are postdoctoral fellows with the Fonds voor Wetenschappelijk Onderzoek, Vlaanderen.

Competing interests: None.

Ethics approval: The study was approved by the local ethics committee.

Provenance and peer review: Not commissioned; externally peer reviewed.

\section{REFERENCES}

1. Hillier S. Diamonds are forever: the cortisone legacy. J Endocrinol 2007;195:1-6.

2. Rosen J, Miner JN. The search for safer glucocorticoid receptor ligands. Endocr Rev 2005;26:452-64.

3. Schäcke H, Berger M, Hansson TG, et al. Dissociated non-steroidal glucocorticoid receptor modulators: an update on new compounds. Expert Opin Ther Patents 2008;18:339-52.

4. Gossye V, Haegeman G, De Bosscher K. Therapeutic implications of the nuclear factor-kappa B/nuclear receptor cross-talk. Frontiers Biosci 2008;13:4122-43.

5. De Bosscher K, Vanden Berghe W, Haegeman G. Nuclear receptors and NF-kappaB Oncogene 2006;51:6868-86.

6. Louw A, Swart P, de Kock SS, van der Merwe KJ. Mechanism for the stabilization in vivo of the aziridine precursor-(4-acetoxyphenyl)-2-chloro- $N$-methyl-ethylammonium chloride by serum proteins. Biochem Pharmacol 1997;53:189-97.

7. De Bosscher K, Vanden Berghe W, Beck IM, et al. A fully dissociated compound of plant origin for inflammatory gene repression. Proc Natl Acad Sci U S A 2005;102:15827-32.

8. Dewint P, Gossye V, De Bosscher K, et al. A plant-derived ligand favoring monomeric glucocorticoid receptor conformation with impaired transactivation potential attenuates collagen-induced arthritis. J Immunol 2008;180:2608-15.

9. Sliwinska-Stanczyk P, Pazdur J, Ziolkowska M, et al. The effect of methylprednisolone on proliferation of PBMCs obtained from steroid-sensitive and steroid-resistant rheumatoid arthritis patients. Scand J Rheumatol 2007;36:167-71.

10. Kirwan JR. Glucocorticoid resistance in patients with rheumatoid arthritis. Scand J Rheumatol 2007;36:165-6.

11. Kirwan J, Power L. Glucocorticoids: action and new therapeutic insights in rheumatoid arthritis. Curr Opin Rheumatol 2007;19:233-7.

12. Oakley RH, Cidlowski JA. Homologous down regulation of the glucocorticoid receptor: the molecular machinery. Crit Rev Eukaryot Gene Expr 1993;3:63-88. 
13. Schaaf MJ, Cidlowski JA. Molecular mechanisms of glucocorticoid action and resistance. J Steroid Biochem Mol Biol 2002;83:37-48.

14. Buttgereit F, Saag KG, Cutolo M, et al. The molecular basis for the effectiveness, toxicity, and resistance to glucocorticoids: focus on the treatment of rheumatoid arthritis. Scand J Rheumatol 2005;34:14-21.

15. Meyer AS, Schmidt TJ. Differential effects of agonist and antagonists on autoregulation of glucocorticoid receptors in a rat colonic adenocarcinoma cell line. J Steroid Biochem Mol Biol 1997;62:97-105.

16. Dong $Y$, Poellinger L, Gustafsson JA, Okret $S$. Regulation of glucocorticoid receptor expression: evidence for transcriptional and posttranslational mechanisms. Mol Endocrinol 1988;2:1256-64.

17. Bellingham DL, Sar M, Cidlowski JA. Ligand-dependent down-regulation of stably transfected human glucocorticoid receptors is associated with the loss of functional glucocorticoid responsiveness. Mol Endocrinol 1992;6:2090-102.

18. Chikanza IC, Kozaci DL. Corticosteroid resistance in rheumatoid arthritis: molecular and cellular perspectives. Rheumatology (Oxford) 2004;43:1337-45.

19. Arnett FC, Edworthy SM, Bloch DA, et al. The American Rheumatism Association 1987 revised criteria for the classification of rheumatoid arthritis. Arthritis Rheum 1988;31:315-24.
20. De Bosscher K, Schmitz ML, Vanden Berghe W, et al. Glucocorticoid-mediated repression of nuclear factor-kappaB-dependent transcription involves direct interference with transactivation. Proc Natl Acad Sci U S A 1997;94:13504-9.

21. Bradford MM. A rapid and sensitive method for the quantitation of microgram quantities of protein utilizing the principle of protein-dye binding. Anal Biochem 1976;72:248-54.

22. Van den Berghe W, Francesconi E, De Bosscher K, et al. Dissociated glucocorticoids with anti-inflammatory potential repress interleukin-6 gene expression by a nuclear factor-kappaB-dependent mechanism. Mol Pharmacol 1999;56:797-806.

23. Miyazawa K, Mori A, Yamamoto K, Okudaira H. Constitutive transcription of the human interleukin-6 gene by rheumatoid synoviocytes: spontaneous activation of NFkappaB and CBF1. Am J Pathol 1998;152:793-803.

24. Loetscher $\mathbf{P}$, Dewald B, Baggiolini M, Seitz M. Monocyte chemoattractant protein 1 and interleukin 8 production by rheumatoid synoviocytes. Cytokine 1994;6:162-70.

25. Sanden S, Tripmacher R, Weltrich R, et al. Glucocorticoid dose dependent downregulation of glucocorticoid receptors in patients with rheumatic diseases. J Rheumatol 2000;27:1265-70.

26. Norman M, Hearing S. Glucocorticoid resistance - what is known? Curr Opin Pharmacol 2002;2:723-9.

27. Alarid ET. Lives and times of nuclear receptors. Mol Endocrinol 2006;20:1972-81. 